EDUR • Educação em Revista. 2020; 36:e229690

DOI: http://dx.doi.org/10.1590/0102-4698229690

(i) (1) https://creativecommons.org/licenses/by/4.0/

ARTIGO

\title{
O DESIGN UNIVERSAL PARA APRENDIZAGEM E A PEDAGOGIA DAS ESTAÇÕES: AS MÚLTIPLAS TEMPORALIDADES/ESPACIALIDADES DO APRENDER NAS ESCOLAS
}

\author{
ELIZABETE CRISTINA COSTA-RENDERS ${ }^{1}$ \\ ORCID: https://orcid.org/0000-0002-1219-9382 \\ SEAN BRACKEN ${ }^{2}$ \\ ORCID: https://orcid.org/0000-0002-3417-4899 \\ ANA SILVIA MOÇO APARÍCIO 3 \\ ORCID: https://orcid.org/0000-0001-6725-5372
}

\begin{abstract}
RESUMO: Este artigo trata da qualificação dos processos de inclusão escolar, tendo em perspectiva a problematização da hegemonia do tempo/espaço do aprender nas instituições educacionais. Apresenta resultados parciais do projeto de pesquisa $A$ escola para todos perguntando: como o design universal para a aprendizagem pode, aproximado à pedagogia das estações, qualificar as experiências inclusivas nas escolas? Tem como objetivo colocar em questão a hegemonia do tempo/espaço do ensino-aprendizagem nas escolas, tendo em foco as temporalidades/espacialidades da aprendência humana nos termos da aprendizagem narrativa. Metodologicamente, este recorte da pesquisa insere-se numa revisão integrativa sobre o design universal para a aprendizagem (DUA), as temporalidades/espacialidades da aprendizagem e a educação inclusiva. Os resultados desta etapa da pesquisa apontaram que o caso da inclusão escolar de pessoas com deficiência é emblemático quando se trata da demanda pela superação da hegemonia do tempo/espaço linear no processo de ensino-aprendizagem. A aproximação entre o design universal para aprendizagem e a pedagogia das estações apontou que ainda existem tensões conceituais importantes neste processo, especialmente no que diz respeito ao paradoxo inerente às práticas inclusivas: atender ao universal/particular ou dar conta da variabilidade de estratégias sem perder de vista o global. Tal problema emerge, especialmente, quando se coloca em perspectiva os expert learners do DUA. Cumpre informar que as pesquisas estão inseridas no âmbito do projeto regular N. 2017/20862-8, Fundação de Amparo à Pesquisa do Estado de São Paulo (FAPESP).
\end{abstract}

Palavras-chave: Aprendizagem narrativa, Currículo, Design universal para aprendizagem, Educação Inclusiva, Pedagogia das Estações.

\section{UNIVERSAL DESIGN FOR LEARNING AND PEDAGOGY OF SEASONS: THE MULTIPLE TEMPORALITIES / SPACES OF LEARNING IN SCHOOLS}

\footnotetext{
ABSTRACT: This article deals with the qualification of processes of school inclusion, considering the problematization of the hegemony of time / space in learning in educational institutions. It socializes

${ }^{1}$ Universidade Municipal de São Caetano do Sul - USCS. São Caetano do Sul, SP, Brasil. <elizabetecostarenders@gmail.com>

2 Worcester University. Worcester, Inglaterra. <sean.bracken@gmail.com>

${ }^{3}$ Universidade Municipal de São Caetano do Sul - USCS. São Caetano do Sul, SP, Brasil < anaparicio@uol.com.br > Educação em Revista|Belo Horizonte|v.36|e229690|2020
} 
partial results from the research project $A$ school for all by asking: How can universal design for learning, along with station pedagogy, qualify inclusive experiences in schools? Its objective is to question the hegemony of the time / space of teaching and learning in schools, putting in perspective the temporalities / spaces of human learning in terms of narrative learning. Methodologically, this research is part of an integrative review on universal design for learning (UDL), learning times / spaces, and inclusive education. The results of this stage of the research indicated that the case of school inclusion of people with disabilities is emblematic when it comes to the demand for overcoming the hegemony of linear time / space in the teaching-learning process. The approximation between the universal design for learning and the pedagogy of seasons has pointed out that there are still important conceptual tensions in this process, especially regarding the paradox inherent to inclusive practices: addressing the universal / particular or accounting for the variability of strategies without lose sight of the global. Such a problem arises especially when putting expert learners from UDL in perspective. Research grant \#2017/20862-8, São Paulo Research Foundation (FAPESP).

Keywords: Narrative learning, Curriculum, Universal design for learning, Inclusive education, Pedagogy of seasons.

\section{EL DISEÑO UNIVERSAL PARA APRENDIZAJE Y LA PEDAGOGÍA DE LAS ESTACIONES: LAS MÚLTIPLES TEMPORALIDADES/ESPACIALIDADES DEL APRENDER EN LAS ESCUELAS}

RESÚMEN: Este artículo aborda la calificación de los procesos de inclusión escolar, con el fin de problematizar la hegemonía del tiempo / espacio de aprendizaje en las instituciones educativas. Presenta resultados parciales del proyecto de investigación La escuela para todos. Por lo tanto, la pregunta es: ¿cómo puede el diseño universal para el aprendizaje, en línea con la pedagogía de las estaciones, calificar las experiencias inclusivas en las escuelas? Su objetivo es cuestionar la hegemonía del tiempo / espacio de enseñanza-aprendizaje en las escuelas, centrándose en las temporalidades / espacialidades del aprendizaje humano en términos de aprendizaje narrativo. Metodológicamente, esta es una revisión integradora sobre el diseño universal para el aprendizaje (DUA), las temporalidades / espacialidades del aprendizaje y la educación inclusiva. Los resultados de esta etapa de la investigación señalaron que el caso de inclusión escolar de personas con discapacidad es emblemático cuando se trata de superar la hegemonía del tiempo / espacio lineal en el proceso de enseñanza-aprendizaje. La aproximación entre el diseño universal para el aprendizaje y la pedagogía de las estaciones señaló que existen tensiones conceptuales importantes en este proceso, especialmente con respecto a la paradoja inherente a las prácticas inclusivas: prestar atención a lo universal / particular o dar cuenta de la variabilidad de las estrategias sin perder de vista lo global. Tal problema surge, especialmente cuando el concepto del expert leaner se pone en perspectiva. Cabe señalar que la investigación es parte del proyecto regular A escola para todos, proceso no 2017 / 20862-8, Fundación de Investigación de São Paulo (FAPESP).

Palabras clave: Aprendizaje narrativa, Currículo, Diseño universal para aprendizaje, Educación Inclusiva, Pedagogía de las Estaciones.

\section{INTRODUÇÃO}

A qualificação dos processos de inclusão escolar tem sido o problema central das pesquisas realizadas no âmbito do grupo de estudos ACESSI (Acessibilidade Escolar e Sociedade Inclusiva) e do projeto $A$ Escola para Todos. Apresentando resultados parciais desses estudos, este artigo parte da seguinte questão investigativa: como o design universal para a aprendizagem pode, aproximado à pedagogia das estações, qualificar as experiências inclusivas no âmbito do currículo narrativo nas escolas?

Nossa hipótese nesta investigação é que o movimento das diferenças na escola impacta consideravelmente a hegemonia do tempo/espaço linear de aprendizagem, provocando e exigindo novas práticas do currículo em ação nos cotidianos das instituições educacionais. Entendemos o currículo em 
ação no sentido da "impossibilidade do currículo formal fazer jus às experiências imprevisíveis que ocorrem no dia a dia da sala de aula" (MACEDO, 2018, p. 29). Por vezes, as escolas encontram-se paralisadas entre a antiga prática e a demanda do novo paradigma.

Metodologicamente, trabalhamos com a revisão integrativa, tendo em perspectiva a consideração de estudos experimentais e não-experimentais para uma compreensão do design universal para aprendizagem. Combinamos, também, "dados da literatura teórica e empírica, além de incorporar um vasto leque de propósitos: definição de conceitos, revisão de teorias e evidências, e análise de problemas metodológicos" (SOUZA; SILVA; CARVALHO, 2010, p. 103) na abordagem curricular advinda do design universal para aprendizagem.

Neste texto, nosso objetivo é tencionar a hegemonia do tempo/espaço do ensinoaprendizagem nas escolas, colocando em perspectiva as temporalidades/espacialidades da aprendência humana nos termos de uma aprendizagem narrativa. Se o espaço educacional é um espaço de trânsito, aberto, alimentado pela dinâmica da aprendência humana, não pode ser legítimo interrompermos o movimento das diferenças pela hegemonia do tempo/espaço padrão.

Para seguir na problematização da hegemonia do tempo/espaço de aprendizagem nas escolas, nos reportamos, primeiramente, ao design universal para aprendizagem ${ }^{4}$ desenvolvido pelo Center for Applied Special Tecnology (CAST, 2018) como uma abordagem curricular que procura apoiar professores no sentido de minimizar as barreiras curriculares e maximizar a aprendizagem para todos os estudantes, sejam eles com ou sem deficiência. Para tal, o DUA, apoiado nos estudos da neurociência, propõe três princípios balizadores do currículo acessível no sentido de oferecer múltiplos meios para: a representação (do que aprender), a ação e expressão (no como aprender) e o engajamento (no porquê aprender).

A pedagogia das estações (COSTA-RENDERS, 2016), como uma nova metáfora para o processo de ensino-aprendizagem, nos leva à consideração do movimento próprio da aprendência humana, onde a luz do conhecimento chega em tempos e formas diferentes para todos os aprendizes sejam professores ou estudantes (não mais 'alunos' sem luz). Reportamo-nos, portanto, às múltiplas dimensões, temporalidades e espacialidades da aprendência humana nos termos do currículo vivido.

Neste percurso investigativo, no âmbito do grupo de estudos Acessibilidade Escolar e Sociedade Inclusiva (ACESSI), nossas pesquisas (COSTA-RENDERS, 2016) têm apontado que a presença/reivindicação da pessoa com deficiência apresenta-se como um caso emblemático da demanda por novas temporalidades e espacialidades de ensino-aprendizagem nas escolas. Tal qual Rose e Meyer (2006, 2014, 2019), partimos dos estudos com a inclusão escolar de pessoas com deficiência para os estudos do design universal para aprendizagem, buscando qualificar este processo. Neste cenário, tanto o DUA quanto a pedagogia das estações partiram das experiências com as pessoas com deficiência, mas ampliaram sua perspectiva de alcance pedagógico a todos os estudantes no decorrer de suas pesquisas.

No Brasil, autoras como Prais (2017), Zerbato e Mendes (2018), Bock, Gesser e Nuernberg (2018) e Costa-Renders (2019) têm apontado para a relevância das experiências com o DUA no âmbito da educação especial em termos de alargamento das práticas inclusivas nos sistemas escolares. Mas indicam também a necessária ampliação das pesquisas brasileiras sobre o DUA no âmbito da educação inclusiva.

Neste momento, nós apresentamos os resultados da primeira etapa de pesquisa no âmbito do projeto $A$ escola para todos, etapa essa, metodologicamente, pautada numa revisão integrativa sobre o DUA, as temporalidades/espacialidades da aprendizagem e a educação inclusiva. Especialmente, aproximamos o DUA dos estudos sobre a pedagogia das estações, que coloca em questão a imposição do tempo/espaço padrão para a aprendizagem na escola.

Nossa reflexão, neste texto, organiza-se em três eixos. O primeiro trata de O problema do tempo na escola, partindo da contribuição da presença/reivindicação das pessoas com deficiência no campo educacional, a qual denuncia a hegemonia do tempo linear (chrónos) e anuncia as múltiplas dimensões do tempo vivido (kairós) nas escolas. O segundo considera As múltiplas temporalidades/ espacialidades na pedagogia das estaçoes, dando continuidade à indagação por uma escola que não tem pressa e que se abre para o

\footnotetext{
${ }^{4}$ Doravante utilizaremos a sigla original DUA para nomear o design universal para a aprendizagem. Optamos por preservar o campo semântico do termo design (inglês), por entender que o termo desenho (português) pode reduzir o campo semântico do termo original.
} 
movimento das corporeidades desviantes e das múltiplas dimensões da temporalidade/espacialidade da aprendência humana. $O$ terceiro promove uma reflexão sobre $O$ universal e a variabilidade no design universal para a aprendizagem, projetando as bases para abordagens pedagógicas que oportunizam as múltiplas formas de percepção, ação/expressão e engajamento no processo de ensino-aprendizagem.

\section{O PROBLEMA DO TEMPO NA ESCOLA}

Há um tempo predominante na escola? Existe um tempo pedagógico ideal na educação inclusiva? São infinitas e complexas, pela especificidade do tema, as possibilidades de falar do tempo: tempos políticos, tempos produtivos, tempos publicitários, tempos consumistas, tempos biológicos, tempos curtos, tempos longos, tempos simultâneos, tempos sequenciais, tempo universal, tempo singular, etc. Todos esses tempos, de uma ou de outra forma, foram subalternizados, desde a modernidade, pelo tempo linear. E, na escola, foi assim também. O tempo linear transformou-se numa representação universal e hegemônica do tempo que, por consequência, restringe a ocupação e uso do espaço escolar para alguns estudantes.

Espaço, "do latim spatio" (FERREIRA, 2004, p. 803), é um substantivo que denota lugar, local ou distância entre dois pontos que pode, ou não, conter alguma coisa, pode ser uma lacuna. Isso nos remete à espacialidade diferentemente exigida no processo de ensino-aprendizagem. Na perspectiva do paradigma da inclusão, entendemos que o espaço - aquele que "é um lugar praticado" (CERTEAU, 1994, p. 202) - deve ser praticado por todas as pessoas que assim o desejarem. Portanto, tendo em perspectiva a equiparação de oportunidades na escola para os diferentes estudantes, há que problematizarmos a determinação do tempo padrão para a espacialidade (lugar ocupado) da aprendizagem humana.

Tempo, "do latim tempus", é um substantivo que denota "a sucessão dos anos, dos dias, das horas, etc. que envolve, para o homem, a noção de presente, passado e futuro" (FERREIRA, 2004, p. 1930). Denota, ainda, "O momento ou ocasião apropriada (ou disponível) para que uma coisa se realize" (FERREIRA, 2004, p. 1930). Pode ser época, pode ser estação, pode ser período e recebe muitos adjetivos, como absoluto, composto, compartilhado, local, universal, etc. $\mathrm{Na}$ ótica do paradigma da inclusão, no entanto, entendemos que o tempo é plural e provisório e nos remete às diferentes temporalidades. Temporalidade, do latim temporalitate, é um substantivo que denota o provisório, a interinidade. No campo da educação inclusiva, essa perspectiva nos apoia na problematização do tempo fixado no relógio para a aprendizagem.

Se, por um lado, na história, progresso, modernização, desenvolvimento e globalização constituíram o seu sentido único na linha linear do tempo, encurtando espaços de uns e alargando espaços de outros. Na educação, por outro lado, a regulação de um sistema, os currículos prescritivos e a tentativa de fixação do marco temporal das fases do desenvolvimento humano privilegiaram o tempo chrónos (tempo do relógio, tempo medido rigorosamente, tempo marcado e fixado) em detrimento do tempo kairós (tempo da vida, tempo oportuno, tempo cíclico, tempo móvel e provisório), legitimando a marcação, a seleção e a exclusão nos sistemas escolares.

Em ambos os casos, na sociedade e na escola, o que se produziu foi a naturalização do atraso e da não-existência de alguns que, na forma do resíduo, não couberam no tempo linear de um sistema. O tempo linear é, portanto, nos termos de Santos (2008), um modo de produção da não-existência. Noutra direção, Foucault (1999) aponta para a relação das instituições educacionais com o poder dos signos temporais, em que cada programa deve ser cumprido no seu tempo. Na consciência das exigências do tempo, o comportamento é pautado pelas determinações do controle disciplinar.

Segundo Assmann (1998), há, por outro lado, a experiência do tempo vivo, individual e coletivo, o qual implica pluralidade simultânea. Esta discussão preconiza a crônica O tempo nos Três Tempos:

\footnotetext{
- Tenho que me apressar o tempo urge. Hoje, acordei, não, pelo grito das três experiências de Clarice Lispector, mas, sim, por um mito - O Tempo. O tempo do aprender foi sequestrado e, agora, deseja sequestrar-me em três tempos.

- Professora, não deu tempo! Fiz tudo o que combinamos, mas o semestre acabou e o livro não ficou pronto. E agora, abandono o que começamos? Quando o livro estiver pronto, o estudante não mais precisará dele!
} 


\begin{abstract}
- Professora, não deu certo, o tempo acabou! A partir de amanhã, depois do fechamento das notas no sistema, a aluna estará reprovada. Todas as atividades planejadas para a flexibilização do tempo da avaliação estarão perdidas, a não ser que, façamos uma retificação de nota, após a reprovação, no sistema. O que eu faço? Reprovo a aluna?

- Professora, sinto muito, não vai dar para pagar por mais tempo. Sei que ele tem mais tempo para estudar, por direito, mas não tenho tempo suficiente para trabalhar e conseguir o valor da mensalidade escolar do meu filho. Preciso mudar de escola porque não tenho mais como pagar. Tem alguma bolsa de estudos para pessoa com deficiência na escola?

Pela manhã, sequestrada pelo tempo, lá estava, eu, ao telefone.

- Fernando, sinto muito. Desculpa! O livro que seu filho precisava não ficou pronto.

- Fabíola, não se assuste. No sistema, o estudante vai aparecer reprovado, mas não está. Depois, após as atividades que combinamos, vamos retificar a sua nota, ok?!

- Samuel, infelizmente, não consegui a negociação dos tempos para o pagamento. Sinto muito! (COSTA-RENDERS, 2016, p. 169).
\end{abstract}

Considerando, especificamente, a presença/reivindicação das pessoas com deficiência nas escolas e a flexibilização de processos, esta é a questão que inaugura a crônica sobre $O$ Tempo nos três tempos, mas não se fixa a ela. Questionamos, portanto, como as intencionalidades pedagógicas de maior complexidade esbarram em modelos administrativos fixados no currículo prescritivo. Ou, ainda, que tipo de gestão escolar seria capaz de contribuir para um movimento criativo, rumo ao reconhecimento das diferenças humanas e à religação dos saberes nas comunidades escolares. Tal perspectiva também nos remete à necessária gestão democrática da escola que deve partir de decisões colegiadas da equipe escolar nos termos do currículo vivido na escola.

Muitas vezes, o tempo institucionalizado pela escola não combina com a educação para todos, pois o tempo cronologicamente institucionalizado exclui ao fixar a espacialidade da aprendizagem. Como dizia Assmann (1998), se isto é assim, não é humano - e na pedagogia pode ser desastroso - querer aprisionar a experiência temporal na exatidão dos relógios, porque os relógios não marcam temporalidades vivenciais.

Se há um tempo institucional que predomina no sistema educacional vigente, Assmann o problematiza nos seguintes termos:

A noção do tempo não pode ser facilmente unificada através de uma única representação universal, ou seja, depois de tudo o tempo permanece problemático porque ele inclui facetas não facilmente unificáveis da experiência humana configurada dentro daquelas dimensões de espacialidade que caracterizam o nosso sensoriamento do mundo que nos envolve (ASSMANN, 1998, p. 221).

A espacialidade desse sensoriamento do mundo nos remete à consideração do binômio tempo/espaço. Consideremos, então, o espaço na visão de Michel Certeau. Segundo este autor, "existe espaço sempre que se tomam em conta vetores de direção, quantidade de velocidade e a variável tempo. O espaço é um cruzamento de móveis. É, de certo modo, animado pelo conjunto dos movimentos que aí se desdobram" (CERTEAU, 1994, p. 202). Portanto, o espaço é o lugar praticado. Estas referências sobre o lugar e o espaço são relevantes para uma conceituação do que seria a inclusão sem cair nos ditames da captura dos corpos pelo sistema educacional. Na perspectiva da educação inclusiva, o espaço escolar deve ser praticado por todos que assim o desejarem.

Tomemos como foco a experiência de pessoas com deficiência com o tempo/espaço de aprendizagem. O sensoriamento do mundo pelas pessoas com deficiência, muitas vezes, não passa pelos sentidos que a evolução cultural privilegiou, a saber, a audição e a visão. Disso decorre a constituição das temporalidades/espacialidades diferentes da aprendência para essas pessoas, a começar num exemplo escolar fundamental, o tempo/espaço da leitura.

Ler um texto impresso em Braile, por exemplo, exige mais tempo do que ler um texto impresso em tinta. São diferentes as dimensões da espacialidade das palavras escritas. Elas exigem cada qual o seu tempo vivido. Podemos, ainda, mencionar os caminhos da leitura pelos estudantes surdos. A leitura de um texto pelos estudantes com surdez profunda e proficientes na Libras, requer o exercício paciente e demorado da tradução da língua portuguesa escrita para a língua sinalizada ou da busca por palavras sinônimas que garantam a troca simbólica entre essas diferentes modalidades linguísticas, condição indispensável para a interpretação de um texto. É outro tempo! Ou melhor, são outras 
temporalidades/espacialidades da aprendizagem que exigem outras temporalidades/espacialidades também no ensino.

Se o tempo institucional subalterniza o tempo vivido no ato de ler, estabelecendo um tempo igual e fixo (o padrão universal) para a leitura aos diferentes estudantes, resta aos estudantes, não detentores dos sentidos privilegiados da visão e da audição, a condição de atrasados ou fracassados, o que, facilmente, legitima a exclusão no espaço escolar. Seria possível romper com esta monocultura do tempo padrão na escola?

$\mathrm{Na}$ busca pelo reencantamento da educação, Assmann (1998) aposta no imaginário transtemporal do devir como fluxo de irreversibilidade na sua dimensão cronológica, mas também como enredo do tempo vivo. Para ele, "[...] o tempo institucional deveria estar sempre a serviço de um clima institucional que estimule a sincronização entre tempos cronológicos e tempos vivenciados [...]" (ASSMANN, 1998, p. 235), o que daria corpo, de fato, aos diferentes tempos pedagógicos. Seria este um primeiro passo para a ecologia das temporalidades na educação? É possível garantir o espaço para o devir, em seus tempos complexos e plurais, na escola? Entendemos que respeitar os diferentes modos de sensoriamentos do mundo (a corporeidade humana) exige que trabalhemos com múltiplos tempos pedagógicos nas unidades escolares.

Boaventura de Souza Santos, por sua vez, através da ecologia das temporalidades, numa visão macrossocial, propõe uma multitemporalidade que rompa com as hierarquias entre as diferentes temporalidades - monocrônicas, policrônicas, horárias, vivenciais, contínuas, descontínuas, reversíveis, irreversíveis, etc. Mas Santos adverte que "construir coligações e organizar acções colectivas entre movimentos ou organizações com diferentes regras temporais não é tarefa fácil” (SANTOS, 2008, p. 110). Para o autor, tal dificuldade somente poderá ser ultrapassada com uma aprendizagem mútua que liberte "as práticas sociais do estatuto residual que lhes é atribuído pelo cânone temporal hegemônico" (SANTOS, 2008, p. 110). Seria tal propósito possível também na educação? Pela ecologia dos saberes, seria possível expandir tempos e espacialidades no currículo vivido na escola? Esta pergunta nos aproxima do currículo narrativo (GOODSON, 2007), que se pauta pela aprendizagem narrativa, a qual exige o reconhecimento do tempo vivencial - o kairós. Ou seja, abre espaço e favorece o tempo oportuno da aprendizagem para cada sujeito em sua singularidade.

Numa visão microssocial, há que perguntarmos se a hegemonia do tempo padrão (chrónos) na educação já insensibilizou as pessoas a ponto delas não perceberem as diferentes temporalidades advindas, nas palavras de Assmann (1998), da quase coincidência entre processos existenciais e processos cognitivos. Como, então, é possível romper a governação do cânone temporal hegemônico dos currículos prescritivos nas escolas? Daria para inverter o fluxo corrente do processo de ensino e aprendizagem e propor múltiplas temporalidades/espacialidades transversalizando o tempo pedagógico? Se, para Assmann (1998, p. 231), o "[...] prazer do cérebro/mente acontece quando o tempo do eu e o tempo do ambiente/universo se encontram [...]", poderia estar nessa proposição uma das pistas para as múltiplas temporalidades/espacialidades na abordagem pedagógica e para o retorno do prazer no ato de aprender nas escolas.

Seguindo nesta rota dos tempos na escola, colocamos em questão o tempo/espaço necessário para a aprendizagem do uso de um novo ou diferente recurso. Nos tempos contemporâneos, as tecnologias da informação e comunicação são mecanismos eficazes de acessibilidade, como é o caso dos softwares leitores de tela (Dosvox, Jaws, Virtual Vision, etc), especialmente, para as pessoas com deficiência visual. Todavia, há um atravessamento curricular importante nos processos de oferecimento do atendimento educacional especializado (AEE) no contexto escolar comum.

$\mathrm{O}$ atendimento educacional especializado (AEE) tem inserido novos códigos de leitura e de escrita nos cotidianos das escolas e se colocado como um atravessamento curricular importante quando tensiona as monoculturas do tempo e espaço de aprender no modo padronizado da escola (BRASIL, 2008). Entendemos que o AEE também coloca em xeque o código cultural dominante determinado pela elite no decorrer da história humana. O reconhecimento da língua de sinais e a sua inserção nos cotidianos da escola é um exemplo desse enfrentamento, pois essa é uma língua que sempre existiu, mas foi feita ausente na escola por não atender à etiqueta de comportamento corporal determinada pelas classes dominantes. 
Se o AEE causa um atravessamento curricular importante nas escolas contemporâneas, nos termos da teoria do currículo (SILVA, 2010), há que considerarmos a cultura dominante nas escolas.

O currículo da escola está baseado na cultura dominante: ele se expressa na linguagem dominante, ele é transmitido através do código cultural dominante. As crianças das classes dominantes podem facilmente compreender esse código, pois durante toda sua vida elas estiveram imersas, o tempo todo, nesse código. (SILVA, 2010, p. 35).

No que concerne ao atravessamento relativo à classe social, Marcelo Neri aponta para a correlação deficiência e pobreza ao analisar os resultados do Censo 2000. Ele indica que a "posse de deficiência de um lado, escolaridade e renda de outro, se mostraram inversamente correlacionadas" (NERI, 2003, p.175). Tal perspectiva também confronta o currículo narrativo que, articulado com a vida e as múltiplas formas de sensoriamento do mundo, rompe com o currículo prescritivo que domina a vida dos aprendizes nas escolas.

A Base Nacional Comum Curricular ${ }^{5}$ (BRASIL, 2018) indica que os currículos têm papéis complementares na garantia das aprendizagens essenciais definidas para cada etapa da Educação Básica, pois "tais aprendizagens só se materializam mediante o conjunto de decisões que caracterizam o currículo em ação.” (BRASIL, 2018, p. 17). Ou seja, serão necessárias decisões da comunidade escolar no sentido de adequar as proposições da BNCC à realidade local das unidades escolares ou vice-versa. Dentre estas decisões, a BNCC aponta que é necessário:

[...] decidir sobre formas de organização interdisciplinar dos componentes curriculares e fortalecer a competência pedagógica das equipes escolares para adotar estratégias mais dinâmicas, interativas e colaborativas em relação à gestão do ensino e da aprendizagem;

[...] conceber e pôr em prática situações e procedimentos para motivar e engajar os alunos nas aprendizagens;

[...] selecionar, produzir, aplicar e avaliar recursos didáticos e tecnológicos para apoiar o processo de ensinar e aprender. (BRASIL, 2018, p. 17-18)

Elizabeth Macedo problematiza essa disposição da BNCC, pois, nela, "o currículo em ação é uma releitura do currículo formal que ocorre por ocasião de sua implementação" (MACEDO, 2018, p. 30). Ele pode seguir, portanto, num processo de prescrição.

A instituição de uma base nacional comum curricular num país continental e desigual como o Brasil, por si, carece da determinação de um tempo e de um espaço de aprender vinculado aos conteúdos e às linguagens a eles vinculadas. No entanto, tal imposição desconsidera os atravessamentos curriculares necessários quando trabalhamos na perspectiva da aprendizagem narrativa. Desconsidera, por exemplo, os atravessamentos advindos do AEE como elemento constituinte da escola inclusiva que prima pelo reconhecimento e pelo respeito às diferenças na abordagem curricular. Portanto, como seria possível trabalhar com diferentes temporalidade e espacialidades da aprendência humana por meio da determinação de uma base nacional comum curricular?

Na perspectiva do paradigma da inclusão, essas decisões no campo do currículo em ação nas escolas precisarão transgredir o currículo prescritivo, especialmente quanto à hegemonia do tempo e do espaço padrão imposto ao ensino e à aprendizagem. Nesses termos, entendemos o 'currículo em ação' como o currículo vivido, pois o currículo precisa "englobar mais do que o saber socialmente prescrito a ser dominado, abrindo-se para experiências que permitam ao aluno compreender o seu próprio mundo da vida". (MACEDO, 2018, p. 29). Essa reflexão nos aproxima do currículo narrativo como um processo de ensino-aprendizagem construído pelos sujeitos que partilham esse percurso, considerando a aprendizagem narrativa. "A aprendizagem narrativa, como conceito, procura mudar o foco da aprendizagem da prescritividade de um currículo fortemente definido para acomodar estilos narrativos pessoais e, assim, incentivar o envolvimento e a motivação no processo de aprendizagem" (GOODSON, 2010).

A inclusão, segundo Mantoan (2008, p. 37), “[...] implica uma mudança de paradigma educacional que gera uma reorganização das práticas escolares: planejamentos, formação de turmas,

\footnotetext{
${ }^{5}$ Doravante BNCC.
} 
currículo, avaliação, gestão do processo educativo [...]". Nesse sentido, a inclusão, necessariamente, é transgressora, pois ela aponta para o vazio e cria oportunidades para o novo. Entendemos que a presença/reivindicação das pessoas com deficiência nas escolas está interrompendo o tempo curricular hegemônico, ao impulsionar outras temporalidades/espacialidades da aprendência humana. Essa é uma importante contribuição desse grupo social para a emergência de novas epistemologias nas escolas, nos termos da aprendizagem narrativa.

Entendemos que ainda não superamos a tensão entre o paradigma dominante (o ensino baseado na imposição do padrão universal e comum a todos) e o paradigma emergente (o ensino que se constitui na tensão entre universal/singular nos termos do respeito à singularidade dos aprendizes) nas escolas. Isso requer escolas que não tenham pressa e que estejam abertas ao currículo narrativo nos termos das múltiplas temporalidades e espacialidades da aprendência humana. Sugerimos, nesse sentido, uma nova metáfora que possa nos apoiar como equipe escolar para ressignificar o tempo e o espaço no ensino-aprendizagem - a Pedagogia das Estações.

\section{AS MÚLTIPLAS TEMPORALIDADES/ESPACIALIDADES NA PEDAGOGIA DAS ESTAÇÕES}

As considerações sobre tempo e espaço também nos remetem à questão da simultaneidade e do ritmo no processo de ensino aprendizagem. Com base nos estudos bakhtinianos, Faraco (2010) afirma que "O ritmo pela sua regularidade e previsibilidade, fecha, modela, enforma, predetermina". Portanto, se o ato criador é "essencialmente extrarrítmico: é preciso romper com uma existência ritmada para poder criar. Pelo ritmo só posso ser possuído; nele vivo como sob anestesia" (FARACO, 2010, p. 20). No campo da educação, podemos aproximar essa consideração às limitações e barreiras advindas do tempo escolar marcado linearmente pelo relógio (chrónos), num ritmo padrão hegemônico, pelo controle do uso do espaço nos termos da homogeneidade desejada (padrão universal).

Entendemos que, no cenário de uma instituição educacional pautada pela lógica classificatória e seletiva, o ritmo faz parte de uma engrenagem que não permite desvios, interrupções e variações. Ele nos remete ao autômato, ser composto de mecanismo que lhe imprime determinados movimentos, que é a negação da vocação ontológica de ser-mais (FREIRE, 2005). Nesse sistema, não é possível diferenciar para incluir, pois trata-se de uma engrenagem alimentada pela monocultura rítmica.

Afirmar a contribuição da presença/reivindicação das pessoas com deficiência na escola para novas temporalidades e espacialidades no processo de ensino-aprendizagem diz respeito ao evidenciamento das diferentes formas de sensoriamento do mundo, que rompe com a monocultura rítmica, num movimento de emergência da corporeidade como centro das abordagens pedagógicas inclusivas que, necessariamente, são desviantes. Ou seja, o respeito às diferentes formas de sensoriamento do mundo (ASSMANN, 1998) vem ao encontro das múltiplas dimensões das temporalidades/espacialidades da aprendência humana e exige que as escolas trabalhem com e pela ecologia das temporalidades e dos saberes diferentemente sábios (SANTOS, 2008). Nessa perspectiva, importa considerarmos a metáfora da pedagogia das estações.

\section{Uma nova metáfora para a educação inclusiva}

Temos considerado as estações do ano como uma nova metáfora para a educação inclusiva. As estações se inserem num calendário anual, mas não se fixam a ele. Repetindo-se, a cada ano, continuamente, elas vão e vêm, num movimento cíclico nos tempos e nos espaços. Portanto, elas não ocorrem simultaneamente em todo o mundo, são itinerantes nos termos do movimento do planeta e diferem, em cada hemisfério, pelos solstícios - quando dia e noite têm duração mais longa do ano - e pelos equinócios - ocasiões em que o dia e a noite duram o mesmo tempo e nas quais acontece a mudança de estação. Todavia, vale lembrar que as datas dos equinócios variam de um ano para outro. Há, portanto, variáveis nesse processo, sendo os equívocos possíveis, especialmente, quando se considera as variáveis

na temperatura média das estações por influência das temperaturas dos oceanos. Analogamente a esse movimento, propomos uma pedagogia das estações onde

[...] Vamos considerar que o conhecimento chega a todos em diferentes tempos e espaços respeitando a ecologia dos saberes e temporalidades.

Educação em Revista| Belo Horizonte|v.36|e229690|2020 
[...] Vamos perguntar pelas temporalidades e espaços do aprender humano que não se fixam num tempo pedagógico marcado pela rigidez curricular, mas diferem-se continuamente.

[...] Vamos considerar as variações e trabalhar pela ampliação do grau de influência dos aprendizes na dinâmica curricular [...] (COSTA-RENDERS, 2019, p. 164-165)

Há um tripé conceitual que alicerça a Pedagogia das Estações, a saber: a transição paradigmática no campo da educação, a pluralidade simultânea e a aprendizagem narrativa. A transição paradigmática (SANCHEZ, 2005) diz respeito ao novo que chega com a educação inclusiva, oportunizando o rompimento com o paradigma da escolarização tradicional e suscitando novas formas de aprender e ensinar nas escolas. A pluralidade simultânea (ASSMANN, 1998), por sua vez, problematiza a imposição do chrónos, abrindo-se às diferentes formas de sensoriamento do mundo e às múltiplas implicações dos seus afetamentos (corporeidades/temporalidades/espacialidades) nos processos de ensino-aprendizagem. Esses dois movimentos anteriores exigem o reconhecimento da aprendizagem narrativa (GOODSON, 2010), que muda o foco da aprendizagem por meio de um currículo fortemente influenciado pelos estilos narrativos pessoais e, assim, oportuniza o engajamento dos aprendizes no processo de aprendizagem.

A pedagogia das estações se firma, portanto, numa dinâmica pedagógica que exige alargar espaços e respeitar as multitemporalidades, num movimento curricular cíclico pautado pelo tempo vivo da aprendizagem narrativa (GOODSON, 2010). Considera a indissociabilidade da personalização e universalização do currículo vivido nas escolas, colocando em questão a tensão entre o tempo pedagógico e as temporalidades vivenciais dos diferentes aprendizes.

Partindo dessas premissas, a pedagogia das estações trabalha pela eliminação das imposições de ritmo advindas do paradigma dominante, considerando as tensões próprias à transição paradigmática (SANCHEZ, 2005) na educação contemporânea. Essa abordagem pedagógica busca promover, em movimento constante e não linear, a aprendizagem para todos, trabalhando epistemologicamente pela antecipação da acessibilidade em suas múltiplas dimensões. Entendemos que a pedagogia das estações nos permite colocar na mesma equação o universal e o particular da aprendizagem, pois é exatamente neste movimento, do múltiplo ao singular, que se dá a dinâmica das temporalidades/espacialidades da aprendência humana.

\section{O UNIVERSAL E A VARIABILIDADE NO DESIGN UNIVERSAL PARA A APRENDIZAGEM}

O design universal para aprendizagem é uma abordagem curricular que considera as diferentes redes neurais que influenciam a aprendizagem dos estudantes, a saber, as redes de reconhecimento, redes estratégicas e redes afetivas. Nesse sentido, o DUA se pauta em três princípios que se sustentam na multiplicidade:

Princípio I: Proporcionar modos múltiplos de apresentação (o "que" da aprendizagem). Princípio II: Proporcionar modos múltiplos de ação e expressão (o "como" da aprendizagem). Princípio III: Proporcionar modos múltiplos de autoenvolvimento (o "porquê" da aprendizagem). (CAST, 2011, on-line).

Por meio desses três princípios, o DUA busca apoiar professoras e professores para responder às necessidades de diferentes aprendizes, removendo as barreiras para a aprendizagem e reduzindo a necessidade de adaptações curriculares individuais, o que qualifica a abordagem inclusiva. Há, no entanto, duas indagações a respeito do DUA que passamos a considerar em nossos estudos recentes. Primeiro, qual o campo semântico do universal nessa abordagem curricular? Segundo, como se sustenta a multiplicidade na progressiva constituição de aprendizes diligentes/sabedores, estratégicos/direcionados e motivados/determinados descrita no Guideles version 2. 0 ?

A primeira questão parte do pressuposto de que a categoria 'universal' pode nos remeter a diferentes campos semânticos. Universal, do latim universale, é um adjetivo que denota o "relativo ou pertencente ao universo, ao cosmo. [...] Que é aplicável a tudo. [...] Que é adaptável ou ajustável de modo que possa atender a diferentes necessidades" (FERREIRA, 2004, p. 2021). Portanto, o universal pode ser 
entendido como um padrão de referência para todos, como o ideal. Mas também pode nos remeter ao propósito de ampliar uma perspectiva e alargar as possibilidades de modo a respeitar as diferenças.

No campo da educação inclusiva, estes dois sentidos apontam para um paradoxo a ser considerado: o universal e particular são elementos constitutivos da proposta curricular inclusiva. A educação inclusiva pauta-se nesse movimento do particular/universal ou do singular/plural, pois respeita a complexa condição humana nos termos do que Morin (2003) nomeia como unodiversidade do ser humano.

Entendemos que o paradoxo do universal/particular está contemplado no DUA, pois nele o universal diz respeito a tornar o mais abrangente possível e os seus princípios não se pautam pelo padrão monocultural. Ao trabalhar com a antecipação curricular dos múltiplos meios e formas, o DUA aponta que:

[...] não há um meio de representação que seja ideal para todos de forma igualitária. [...] não existe um meio de ação e expressão que será ideal para todos os estudantes. [...] não há um meio de engajamento que atenderá de forma ideal todos os estudantes em todos os contextos. (CAST, 2018)

Os princípios do DUA pautam-se pelos múltiplos meios e possibilidades, reconhecendo e respeitando a singularidade de cada aprendiz sem perder de vista o universal, no sentido de ampliar meios e formas de oferecer o conhecimento, de modo a poder atender as diferentes necessidades dos aprendizes. Isso nos remete à variabilidade, um conceito de grande relevância no DUA, que aponta para a variação interindividual e intraindividual. Há uma variedade de fontes que podem influenciar a variação individual em interessar-se, incluindo neurologia, cultura, relevância pessoal, subjetividade e conhecimento de mundo.

Alguns aprendizes são altamente envolvidos pela espontaneidade e novidade, enquanto outros não são engajados, são até assustados, por esses aspectos, preferindo uma rotina rígida. Alguns aprendizes podem gostar de trabalhar sozinhos, enquanto outros preferem trabalhar com seus pares. Na realidade, não há um meio de engajamento que seja ótimo para todos os aprendizes em todos os contextos. (CAST, 2018)

A variabilidade dos estudantes é uma das forças no DUA (BOCK et al., 2018). "A variabilidade é a mistura dinâmica e em constante mudança de forças e desafios que compõe cada aprendiz". (ROSE; MEYER; GORDON, 2014, p. 48). Há, portanto, a perspectiva afetiva que também difere no percurso acadêmico do próprio aprendiz, a variabilidade na dimensão intraindividual.

O mesmo estudante difere em tempo e circunstância. Seus interesses mudam à medida que o aprendiz se desenvolve e ganha novos conhecimentos e habilidades, à medida que se desenvolve como criança, adolescente ou adulto. Por conseguinte, pedagogicamente, é importante despertar o interesse dos diferentes estudantes por diferentes meios que reflitam as diferenças inter e intraindividuais. Ou seja, o DUA e a pedagogia das estações consideram a singularidade tanto de processos quanto de cada estudante, mas sem perder de vista o global e as relações de interdependência em todo o processo de ensino aprendizagem.

Nesse cenário, uma abordagem curricular que pretenda remover as barreiras para aprendizagem, segundo o DUA (CAST, 2018), deve:

a) Considerando as redes de reconhecimento, fornecer as informações e conteúdos em distintas modalidades e formatos que permitam ao usuário fazer os ajustes necessários. Mas também trabalhar com símbolos linguísticos universais que possibilitam a compreensão por diferentes pessoas de diferentes contextos culturais, oferecendo esclarecimentos e suportes para a decodificação. Atualmente, as tecnologias digitais são instrumentos importantes nesse sentido.

b) Considerando as redes estratégicas, fornecer opções para a ação física mediante diferentes tecnologias de apoio, oferecer opções para comunicação e expressão com diferentes instrumentos para construção e composição, oferecer opções para as funções executivas por meio do planejamento de metas e estratégias de desenvolvimento, potencializando a capacidade do aprendiz de monitorar o seu progresso na aprendizagem. 
c) Considerando as redes afetivas, envolver, sempre que possível, os estudantes na definição de seus próprios objetivos acadêmicos, oportunizando o desenvolvimento de habilidades individuais de autorregulação no sentido de facilitar as habilidades e estratégias pessoais. Mas também estimular o esforço e a persistência com diferentes suportes, criando programas de apoio e a colaboração entre os estudantes.

A multiplicidade, portanto, impede que o DUA seja interpretado como uma abordagem curricular pautada pela imposição de um padrão de ensino-aprendizagem na escola. A esse respeito, Rose (2019) afirma a importância da releitura do DUA por diferentes pesquisadores no mundo, de modo a encontrar novas e diferentes soluções no campo da educação inclusiva.

Retomemos, agora, a nossa segunda indagação sobre o DUA: como se sustentam as múltiplas possibilidades na progressiva constituição de aprendizes diligentes/sabedores, estratégicos/direcionados e motivados/determinados descrita no Guideles version 2. 0 (CAST, 2011)? Esse problema partiu de uma análise da representação gráfica do Guidelines version 2. 0 (CAST, 2011), a qual se apresenta como uma sequência de ações linearmente numeradas e marcadas por setas sequenciais no sentido do alcance dos expert learners ${ }^{6}$ (CAST, 2011). A representação gráfica da Figura 1 exemplifica esta constatação.

Figura 1: Representação gráfica do Guidelines version 2.0, 2011, com modificações da autora

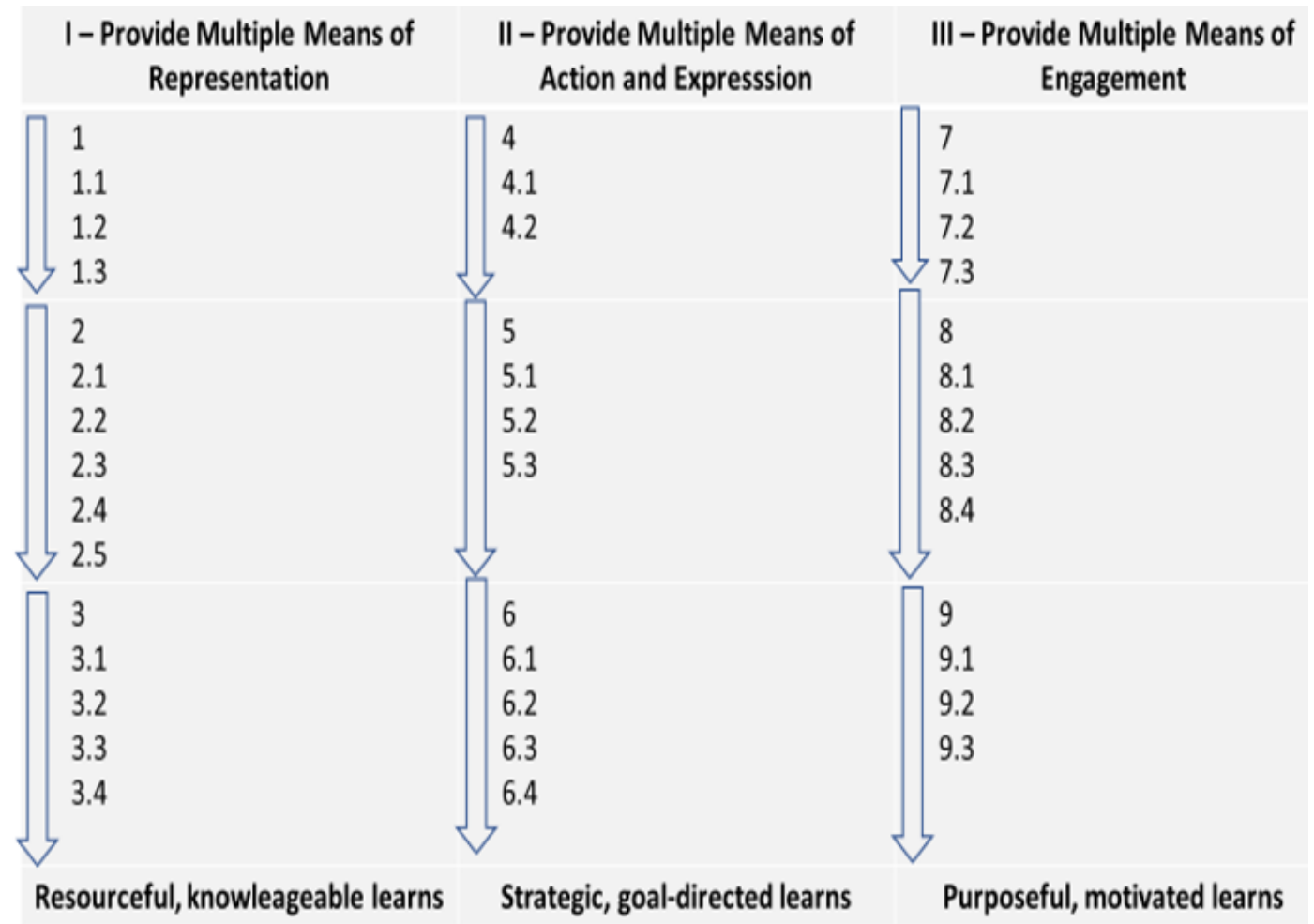

Fonte: CAST, 2011.

Como esta não é a única e definitiva representação gráfica dos princípios do DUA, é possível evidenciar uma tensão epistemológica quando colocamos, lado a lado, o Guidelines version 2.0 (CAST, 2011), o Guidelines version 2. 1 (CAST, 2014) e o Guidelines version 2. 2 (CAST, 2018). Este último elimina todos os números e setas no sentido de indicar a não hegemonia do tempo linear nessa abordagem curricular. Insere, ainda, três desenhos do cérebro com a marcação espacial das diferentes redes neurais, como podemos visualizar na Figura 2.

\footnotetext{
${ }^{6}$ Optamos por manter o termo em inglês porque a tradução para o português para aprendizes especialistas ou especializados poderia reduzir a proposta do DUA.
} 
Figura 2: Representação gráfica do Guidelines version 2.2, com modificações da autora

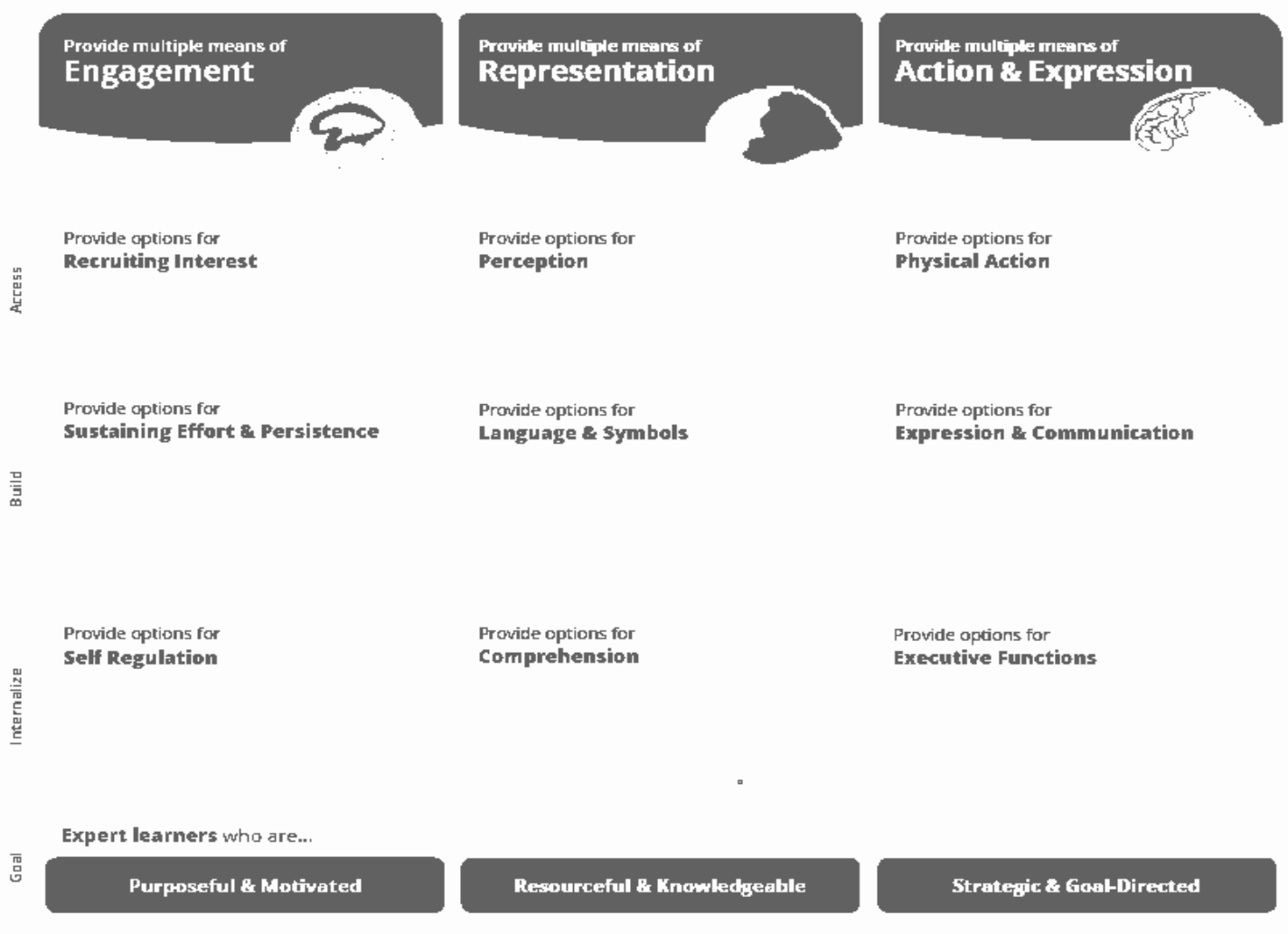

Fonte: CAST, 2018.

Percebemos um significativo avanço nessa representação gráfica quando ela rompe com a linearidade temporal e espacial aplicada anteriormente aos princípios do DUA. Eliminam-se as setas direcionais e os números sequenciais que os fixavam na seta do tempo linear. No Guidelines version 2. 2, as múltiplas dimensões do processo de ensino-aprendizagem ganham maior destaque e a representação gráfica permite uma flexibilização curricular no sentido da aprendizagem narrativa, a qual é influenciada pelos estilos pessoais do aprendiz. Nesse cenário, a consideração da pluralidade simultânea torna-se possível e recomendável.

Entendemos que o tema flexibilização curricular nos remete ao movimento cíclico da pedagogia das estações, onde é possível também vivenciar a ambivalência das fronteiras das áreas do conhecimento, tal qual acontece com as estações do ano nos períodos de transição entre elas. A mudança de uma para outra estação não acontece como está marcada nos dias do calendário, pois a transição traz em si a ambivalência que lhe é própria.

Com a vivência do tempo cíclico, em espiral, na pedagogia das estações, também são possíveis os espaços misturados e o uso dos recursos diferenciados para a construção do conhecimento com base na pluralidade simultânea. A seguir, apresentamos uma representação gráfica (Figura 3) que aproxima a perspectiva narrativa da pluralidade simultânea aos princípios do DUA, numa marcação temporal não linear. Por isso, a imagem inacabada. 
Figura 3: Representação gráfica da interface entre a Pedagogia das Estações e o DUA

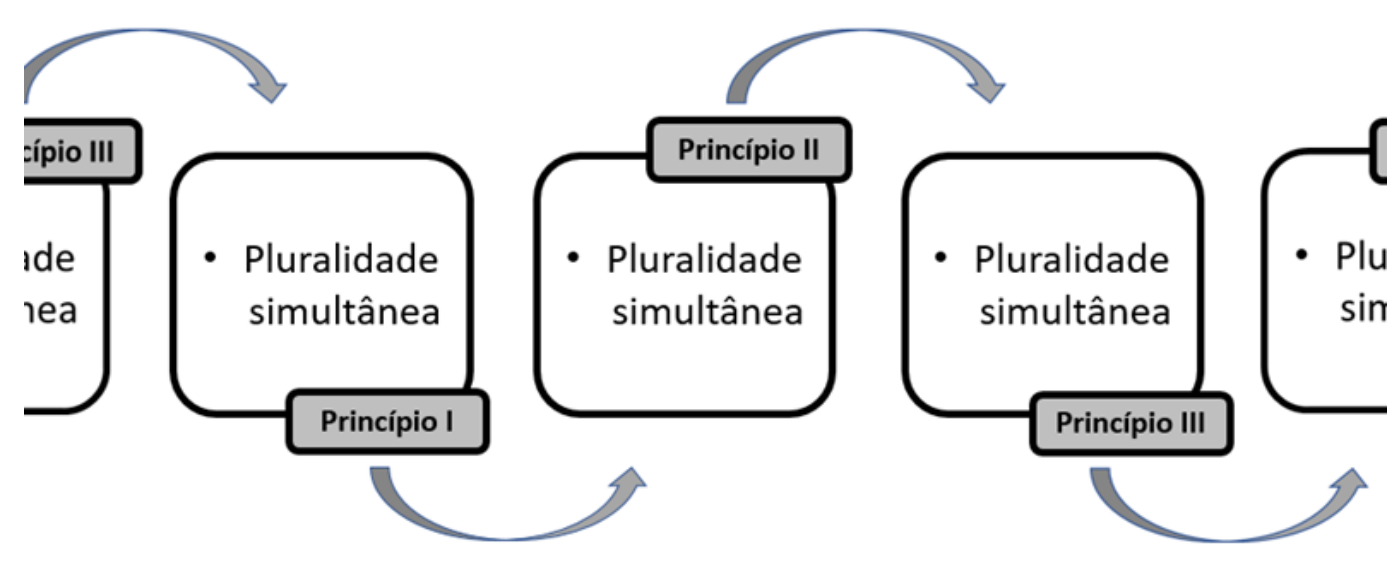

Fonte: elaborado pela autora, 2019.

Nesta interface entre a pluralidade simultânea proposta pela pedagogia das estações e os princípios do DUA, buscamos flexibilizar nos princípios, rompendo a sua sequência e deixando as fronteiras abertas. Visamos oportunizar a superação do currículo prescritivo que, segundo Goodson (2007, p. 242), “[...] busca imparcialmente definir os principais ingredientes do desenvolvimento do estudo [...]", marcando fronteiras no processo de construção do conhecimento e inibindo as múltiplas representações, expressões e interesses na escola.

Aproximando-nos, novamente, das diretrizes do DUA:

[...] não pretendem ser uma "prescrição", mas um conjunto de sugestões que podem ser aplicadas para reduzir barreiras e maximizar as oportunidades de aprendizado para todos os estudantes. Elas podem ser combinadas de acordo com objetivos específicos de aprendizagem e podem ser aplicadas a áreas e contextos específicos. (CAST, 2018).

Ou seja, os princípios do DUA também rompem com o currículo prescritivo, aproximandose da abordagem curricular narrativa. No entanto, retomando a representação gráfica dos princípios do DUA, no Guidelines version 2. 2, permanece o objetivo de alcançar os expert learners que são "indivíduos que sabem aprender, que já aprenderam muito e que desejam aprender mais" (ROSE; MEYER; GORDON, 2014, p. 49). A esse respeito, o CAST esclarece que os Guidelines "levam, em conjunto, ao objetivo final do DUA: desenvolver expert learners que sejam, cada um a seu modo, engenhosos e conhecedores, estratégicos e focados em seus objetivos, com propósito e motivados" (CAST, 2018). Tal afirmação nos remete a uma série de questões: como ficariam os aprendizes que não se encaixam nos adjetivos do expert learn - engajado, engenhoso, conhecedor, estratégico, direcionado, etc.? Todo estudante carregaria em si os adjetivos do expert learner? Faltaria no DUA a perspectiva da vulnerabilidade como condição humana? Ser um expert learn é uma imposição a todos os estudantes ou esse objetivo se coloca como um horizonte utópico dos professores e professoras? De que maneira a demanda pelo expert learner articula-se aos princípios de universal/singular? Nossas pesquisas sobre o DUA pretendem seguir nestas indagações. Por ora, trabalhamos na discussão do tempo/espaço da aprendizagem.

\section{Aproximações entre a pedagogia das estações e o DUA}

A perspectiva da pedagogia das estações propõe um dinâmico movimento curricular que não se fixa ao tempo/espaço linear, mas trabalha com a pluralidade simultânea que problematiza a imposição do chrónos, abrindo-se às diferentes temporalidades/espacialidades da corporeidade humana em seu 
sensoriamento do mundo. Isso nos remete, nos termos do DUA, à relevância de oportunizar múltiplas formas de representação e percepção dos saberes nas escolas simultaneamente a todos os aprendizes.

Para reduzir as barreiras à aprendizagem, é importante garantir que a informação chave seja igualmente perceptível para todos os aprendizes: 1) fornecendo a mesma informação através de diferentes modalidades (por exemplo, através da visão, audição ou toque); 2) fornecendo informações em um formato que permita o ajuste pelo usuário (por exemplo, texto que pode ser ampliado, sons que podem ser amplificados). Tais representações múltiplas não só garantem que a informação seja acessível aos aprendizes com deficiências sensoriais e perceptivas particulares, mas também que seja mais fácil de acessar e compreender para muitos outros. Uma importante estratégia de ensino é assegurar que representações alternativas sejam fornecidas não só para a acessibilidade, mas para clareza e compreensão por todos os aprendizes (CAST, 2018).

O DUA propõe movimentos pedagógicos numa intencionalidade didática marcada pelo romper barreiras e criar acesso, bem como considera a necessária compreensão por parte de todos os estudantes nas escolas. Não se trata de diferenciação por causa da deficiência, mas, sim, do dinâmico movimento curricular no sentido de diferenciar para incluir, sempre, a todos, o que vem ao encontro da perspectiva da pluralidade simultânea. Trata-se do respeito às múltiplas espacialidades/temporalidades da aprendência humana, oportunizando as diferentes estações de construção do conhecimento, onde seja possível também inverter os inícios a partir dos desejos, possibilidades e habilidades de cada um.

Entendemos que há, no entanto, uma diferença entre a pedagogia das estações e o DUA. A primeira trabalha com a indissociabilidade do tempo/espaço de aprendizagem e se propõe a atender aos diferentes aprendizes por meio de diferentes estações de conhecimento, simultaneamente oferecidas, sem a fixação do tempo/espaço de acesso a elas. Ou seja, dá centralidade às multitemporalidades no processo pedagógico. O que se perdeu, por uma ou outra razão, também poderá voltar a ser oferecido, tal qual o movimento cíclico das estações do ano, pois todos os elementos permanecerão disponíveis a todos que desejarem acessá-los.

O DUA, por sua vez, dá centralidade ao oferecimento dos múltiplos meios e modos de representação, ação/expressão e engajamento dos aprendizes sem colocar luzes à questão do tempo/espaço de aprendizagem. Talvez possamos dizer que o DUA foca, especialmente, a influência do aprendiz no currículo.

A pedagogia das estações pauta-se, predominantemente, nas multitemporalidades e o DUA na multiplicidade dos meios e formas no processo de ensino-aprendizagem. Ambos têm em comum a centralidade do processo de ensino-aprendizagem nos termos da proposição de abordagens pedagógicas que apoiem professoras e professores no sentido da construção de currículos narrativos que possam ser afetados pelas diferenças de todos os aprendizes.

\section{CONSIDERAÇÕES FINAIS}

Neste texto, nós apresentamos os resultados de uma revisão integrativa sobre o DUA, as temporalidades/espacialidades da aprendizagem e a educação inclusiva. Especialmente, aproximamos o DUA dos estudos sobre a pedagogia das estações, que problematiza a imposição do tempo/espaço padrão para a aprendizagem na escola e aponta para a relevância da abordagem curricular narrativa no sentido do respeito aos diferentes aprendizes e do alargamento das temporalidades/espacialidades da aprendizagem nas escolas.

Ao retomarmos a questão sobre como a pedagogia das estações e o design universal para a aprendizagem podem qualificar as experiências inclusivas no âmbito do currículo narrativo nas escolas, ambos nos ajudam a colocar luzes, pelo menos, sobre três dimensões que devem permear a construção da escola inclusiva.

Primeiro, há que colocarmos em questão o fluxo corrente de um processo de ensino e aprendizagem fixado no tempo/espaço padrão do aprender e ensinar. A discussão epistemológica provocada pela pedagogia das estações e pelo DUA nos remete às múltiplas temporalidades/espacialidades, transversalizando o tempo pedagógico nas escolas que pretendem ser 
inclusivas. Muitas vezes, garantir as condições de acessibilidade e a equiparação de oportunidades educacionais depende das provocações e inversões no currículo em ação nas escolas. O caso dos aprendizes com deficiência tem sido emblemático nesse sentido. Conhecer o mundo sem imagens visuais, passando pela aprendência com as memórias táteis e auditivas, bem como conhecer o mundo somente por imagens visuais numa dinâmica e aguçada visão panorâmica, apontam para temporalidades/espacialidades novas, nunca sequer consideradas nas unidades escolares. Os recursos de acessibilidade, portanto, têm um potencial amplo. Eles não apenas quebram barreiras imediatas para alguns indivíduos, mas ampliam e potencializam as novas aprendizagens na escola, tanto para estudantes quanto para professores e professoras.

Em segundo lugar, e em consequência da revisão epistemológica anterior, a abordagem inclusiva deve trabalhar pela ampliação do grau de influência dos aprendizes na dinâmica curricular. Todavia, isso somente é possível no movimento constante da convivência com as diferenças, o que exige disponibilizar, de forma simultânea, as diferentes estações do conhecimento para todos os aprendizes na escola. É preciso fornecermos os suportes necessários para garantir que todos os aprendizes tenham acesso ao conhecimento e liberdade para engajar-se na aprendizagem. Isso também permite trabalhar o conteúdo ético a todo o momento, pois, tal qual preconizado pela educação inclusiva, importa continuamente perguntarmos por como habitamos o mundo de forma a oportunizar o aprender e viver de forma digna para todos, especialmente, nas escolas. Há que perguntarmos, portanto, constantemente, como habitamos juntos e diferentemente a escola.

A terceira dimensão a ser considerada no sentido de qualificar os processos inclusivos nas escolas, numa interface entre a pedagogia das estações e o DUA, coloca luzes sobre a necessária emergência de tempos e espaços flexíveis para a construção do conhecimento, sem abandonar conhecimentos consolidados pela humanidade, os quais também contribuem para que a aprendizagem se efetive nas escolas. Entendemos que a variabilidade não exclui a universalidade do conhecimento, o que nos remete ao paradoxo inerente à educação que pretenda ser inclusiva e sustentável - o antigo e o novo são constitutivos do processo educacional, como já nos alertava Hannah Arendt (2009, p. 223): “a essência da educação é a natalidade, o fato de que seres nascem para o mundo". A educação é o campo em que sempre chega o novo conhecimento para encontrar-se ou confrontar-se com o que já fora constituído, o qual também é provisório porque pode ser impactado pela novidade que se repete, tal qual o movimento das diferenças na história humana.

Entendemos que o planejamento curricular não deve, em nome do singular, abandonar a consideração e disponibilização dos saberes já construídos pela comunidade humana no decorrer da história - trata-se da garantia do acesso ao patrimônio cultural da humanidade como um bem comum a ser partilhado também nas unidades escolares.

\section{REFERÊNCIAS}

ARENDT, Hannah. Entre o passado e do futuro. São Paulo: Perspectiva, 2009.

ASSMANN, Hugo. Reencantar a educação: rumo à sociedade aprendente. Petrópolis, RJ: Vozes, 1998.

BRASIL/MEC. Base Nacional Comum Curricular. Brasília, 2018. Disponível em: $<$ http://basenacionalcomum.mec.gov.br/images/BNCC_EI_EF_110518_versaofinal_site.pdf>. Acesso em: 02 maio 2019.

BOCK, Geisa; GESSER, Marivete; NUERNBERG, Adriano. Desenho Universal para a Aprendizagem: a produção científica no período de 2011 a 2016. Rev. Bras. Educ. Espec. [online], Bauru, SP, , vol. 24, n. 1, p. 143-160, jan. 2018. DOI: http://dx. doi. org/10. 1590/s141365382418000100011. 
CAST. The three principles of UDL. Disponível em: < http:/ /www.udlcenter.

org/aboutudl/whatisudl/3principles>. Acesso em: 26 ago. 2017.

CAST. Universal Design for Learning guidelines version 2. 0. Wakefield, MA: Author, 2011.

CAST. Universal Design for Learning guidelines version 2. 1 [graphic organizer]. Wakefield, MA: Author, 2014.

CAST. Universal Design for Learning guidelines version 2. 2 [graphic organizer]. Wakefield, MA: Author, 2018.

CAST. UDL and learning brain. Wakefield, MA: Author, 2018.

CERTEAU, Michel de. A invenção do cotidiano. Petrópolis, RJ: Vozes, 1994.

COSTA-RENDERS, E.C. A inclusão na universidade: as pessoas com deficiência e novos caminhos pedagógicos. Curitiba: Editora Prismas, 2016.

COSTA-RENDERS, E. C. Pedagogy of Seasons and UDL: the multiple temporalities of learning involving the university as a whole. In: BRACKEN, S.; NOVAK, K. (Org.). Transforming Higher Education Through Universal Design for Learning an International Perspective. 1ed. London: Routledge, 2019, v. 1, p. 159-178.

FARACO, Carlos. O espírito não pode ser o portador do ritmo. Bakhtiniana, São Paulo, v. 1, n. 4, p. 17-24, $2^{\circ}$. sem. 2010.

FERREIRA, Aurélio. Novo dicionário Aurélio da língua portuguesa. Curitiba: Positivo, 2004.

FREIRE, Paulo. Pedagogy of the oppressed. London and New York: Continuum, 2005.

FOUCAULT, Michel. Vigiar e punir: nascimento da prisão. Petrópolis, RJ: Vozes. 1999.

GOODSON, Ivor. Currículo, narrativa e o futuro social. In: Revista Brasileira de Educação, v. 12, n. 35, maio-ago. 2007.

GOODSON, Ivor et al. Narrative Learning. London and New York: Routledge, 2010.

MADUREIRA, Isabel; NUNES, Clarice. Desenho universal para aprendizagem: construindo práticas pedagógicas inclusivas. In: Da Investigação às Práticas, Lisboa, v. 5, n. 2, p. 126-143, 2015.

MANTOAN, Maria Teresa Eglér. O desafio das diferenças nas escolas. Petrópolis, RJ: Vozes, 2008.

MACEDO, Elizabeth. “A Base é a base”. E o currículo o que é? In: AGUIAR, Márcia; DOURADO, Luiz. A BNCC na contramão do PNE 2014-2024: avaliação e perspectivas. Recife: ANPAE, 2018. 61 p.

MORIN, Edgar. O Método V: a humanidade da humanidade - a identidade humana. Porto Alegre, RS: Sulina, 2003.

NERI, Marcelo (et al.). Retratos da deficiência no Brasil. Rio de Janeiro: FGV/IBRE, CPS, 2003. 
PRAIS, Jacqueline. Desenho universal para aprendizagem nas produções brasileiras. Disponível em: < https://educere.bruc.com.br/arquivo/pdf2017/27318_13667.pdf>. Acesso em: 09 set. 2017.

ROSE, David; MEYER, Anne. A practical reader in universal design for learning. Cambridge: Harvard Education Press, 2006.

ROSE, David; MEYER, Anne; GORDON, David. Universal design for learning: Theory and practice, Wakefield MA: CAST, 2014.

ROSE, David. Foreword. In: BRACKEN, Sean; NOVAK, Katie. (org.). Transforming Higher Education Through Universal Design for Learning an International Perspective. 1ed. London: Routledge, 2019, p. XVIII-XX.

ROSE, David; MEYER, Anne. The future is in the margins: the role of technology and disability in educational reform. Disponível em: <http://www. udlcenter. org/sites/udlcenter.

org/files/MeyerRose_FutureisintheMargins. pdf>. Acesso em: 09 mar. 2019.

SANCHEZ, Pilar Arnaiz. Educação inclusiva: um meio de construir escolas para todos no século XXI. In: MEC. Inclusão Revista da Educação Especial, Brasília, DF, v.1, n. 1, p. 1-17, out. 2005.

Disponível em: < http://portal.mec.gov.br/seesp/arquivos/pdf/revistainclusao1. pdf>. Acesso em: 09 mar. 2019.

SANTOS, Boaventura de Sousa. A gramática do tempo: para uma nova cultura política. São Paulo: Cortez, 2008.

SILVA, Tomaz Tadeu. Documentos de identidade: uma introdução às teorias do currículo. Ed. 10. Belo Horizonte: Autêntica Editora, 2010.

SOUZA, Marcela; SILVA, Michelly; CARVALHO, Rachel. Revisão integrativa: o que é e como fazer. Einstein, São Paulo, v. 8, n. 1, p. 102-106, mar. 2010; DOI: 10. 1590/s1679-45082010rw1134.

ZERBATO, Ana Paula; MENDES, Enicéia Gonçalves. Desenho universal para a aprendizagem como estratégia de inclusão escolar. Educação Unisinos, São Leopoldo, RS, v. 22, n. 2, p. 147-155, abr.-jun. 2018. DOI: 10. 4013/edu. 2018. 222. 04. 